\title{
Regresión. Las nuevas políticas para medios comunitarios en Argentina
}

\author{
Regression. The new community media \\ policies in Argentina
}

\begin{abstract}
Verónica Longo | Universidad Nacional de San Luis (UNSL) Docente e investigadora de la Facultad de Ciencias Humanas, en la Universidad Nacional de San Luis. Es licenciada en Comunicación Social y magíster en Dirección de Comunicaciones Institucionales. Email: vblongo@hotmail.com
\end{abstract}

María Soledad Segura | Universidad Nacional de Córdoba Doctora en Ciencias Sociales, magíster en Comunicación y Cultura Contemporánea. Docente de la Escuela de Ciencias de la Información de la Universidad Nacional de Córdoba (UNC) e investigadora asistente del Consejo Nacional de Investigaciones Científicas y Técnicas (Conicet). Email: maria.soledad.segura@gmail.com.

Emilia Villagra | Universidad Nacional de Salta Licenciada en Ciencias de la Comunicación de la Universidad Nacional de Salta y becaria interna doctoral de Conicet. Email: emi_villagra_02@hotmail.com

Ana Laura Hidalgo | Universidad Nacional de San Luis (UNSL) Licenciada en Comunicación Social por la Universidad Nacional de San Luis (UNSL), especialista en Gestión Social por la Universidad Nacional de Cuyo

(UNCUYO).Becaria doctoral de Conicet. Email: hidalgo.analaura@gmail.com.

Natalia Traversaro | Universidad Nacional de Córdoba Licenciada en Comunicación Social por la Universidad Nacional de Córdoba, diplomada en Estudios Avanzados y doctora en Estudios Latinoamericanos por la Universidad Complutense de Madrid. Email: nataliatraversaro@gmail.com.

\begin{abstract}
Alejandro Linares | Universidad Nacional de San Luis Licenciado en Ciencias de la Comunicación de la Universidad de Buenos Aires (UBA). Maestrando en Comunicación y Cultura en la misma institución. Becario del Consejo Nacional de Investigaciones Científicas y Técnicas (Conicet) en el Instituto de Estudios sobre América Latina y el Caribe (IEALC) de la UBA. Email: linaresale@hotmail.com.
\end{abstract}


Larisa Kejval | Universidad de Buenos Aires (UBA) Licenciada en Ciencias de la Comunicación y magíster en Comunicación y Cultura por la Universidad de Buenos Aires. Email: larisakej@yahoo.com.ar.

Natalia Vinelli | Universidad de Buenos Aires (UBA) Licenciada en Ciencias de la Comunicación Social de la Universidad de Buenos Aires (UBA). Especialista en Planificación y Gestión de la Actividad Periodística y magister en Periodismo, ambos por la UBA. Doctoranda en Ciencias Sociales (FCSoc UBA). Email: nataliaprensa@yahoo.com.ar.

\section{Resumen}

Nuestra hipótesis es la siguiente: históricamente, las políticas públicas de comunicación ayudaron a construir una posición de desventaja en términos de sostenibilidad económica de los medios comunitarios, populares y alternativos de Argentina, con respecto a los medios de propiedad privada con fines de lucro y a los estatales. Después de una breve etapa entre 2009 y 2015 en la que las políticas dirigidas al sector no lucrativo se orientaron - con sus demoras y problemas - a su legalización y fomento, las políticas del gobierno actual, aunque no modificaron el marco legal, restauran las persecuciones a las radios en situación de ilegalidad forzosa.

Palabras Claves: medios comunitarios; políticas de comunicación; desigualdad; regresión.

\section{Abstract}

Our hypothesis is as follows: historically, public communication policies helped to construct a disadvantageous position in terms of economic sustainability of the popular, alternative, and community media of Argentina, with respect to private for profit media and to state media. After a brief period between 2009 and 2015 in which policies aimed at the non-profit sector were oriented, with their delays and problems, to their legalization and promotion, the policies of the current government, although they did not modify the legal framework, restore the persecutions against these radios in situation of forced illegality.

Keywords: Community media; communication policies; inequality; regression. 


\section{Introducción}

El artículo analiza en qué medida las políticas públicas de comunicación contribuyeron a construir la posición de profunda desventaja en términos de sostenibilidad económica de los medios comunitarios, populares y alternativos de Argentina con respecto a los medios de propiedad privada con fines de lucro y a los de propiedad estatal.

Asumimos los procesos de formulación de las políticas públicas como procesos conflictivos en los que se ponen en juego intereses ligados a posiciones desiguales de jerarquía y poder de diversos actores sociales e institucionales con distintos recursos a su disposición. Por lo tanto, este análisis desafía la visión de las políticas públicas definidas exclusivamente por las élites políticas y económicas. En consecuencia, actores aparentemente débiles podrían llegar a tener cierta capacidad de influencia en esos procesos, como resultado de sus demandas al Estado. Este enfoque pone de relieve también que las políticas públicas no son totalmente formuladas en el Estado, sino que reconoce las relaciones entre actores estatales, comerciales y sociales (SEGURA Y WAISBORD, 2016).

Entre 2009 y 2015 las políticas dirigidas al sector de medios sin fines de lucro se orientaron - con sus demoras y problemas - a su legalización y fomento. Las políticas del gobierno actual, restauran las persecuciones a las radios en situación de ilegalidad forzosa, aun sin modificar el marco legal.

En primer lugar, se argumenta por qué es necesario que el Estado promueva estas emisoras. Posteriormente, se repasan las políticas dirigidas a ellas $y$, en tercer lugar, se comparan con las orientadas a medios comerciales y estatales. Finalmente, se concluye que la actual gestión del gobierno argentino restaura las políticas que privilegian a las grandes empresas audiovisuales y de telecomunicaciones en desmedro de las radios y televisoras del sector social.

\section{La relevancia de las radios y televisoras comunitarias}

A mediados de la década de 1980 surgieron conjuntos de emisoras que no es posible comprender desde la lógica del capital. En Argentina, como en la mayoría de los países del Cono Sur, las radios y televisoras comunitarias, populares y alternativas emergieron en el contexto de recuperación democrática luego de la más cruenta dictadura cívico-militar de nuestra historia. Durante la transición democrática, múltiples movimientos populares - de derechos humanos, género, pueblos originarios, ambientalistas etc. - se reagruparon. En ese marco, numerosas propuestas de comunicación acompañaron las demandas de estas organizaciones al tiempo que plantearon, desde la ilegalidad, la disputa por el reconocimiento de derechos comunicacionales. Así lo demuestran diversas investigaciones realizadas en el país (ver, entre otras, GERBALDO, 2011).

Entonces y hasta 2009, la radiodifusión estuvo regulada por la Ley 22.285 de Radiodifusión establecida por la Junta Militar en 1980, que vedaba la posibilidad de las organizaciones sin fines de lucro de ser licenciatarias de servicios de comunicación audiovisual. 
Las emisoras "comunitarias", "populares" y "alternativas" - calificativos con los que ellas y sus redes nacionales e internacionales se identifican (KEJVAL, 2013) - ponen en cuestión al lucro como orientador de las prácticas comunicacionales. Además, todas tienen como horizonte explícito la transformación de relaciones sociales de desigualdad.

El antagonismo respecto del sistema de medios hegemónicos resultó constitutivo de la identidad política de estos medios. Cuestionaron las políticas de comunicación de los sucesivos gobiernos nacionales por posibilitar los procesos de centralización de capital, concentración y transnacionalización del sistema mediático (KEJVAL, 2013).

En este contexto, la sanción de una nueva ley de radiodifusión que las incluyera como actores con plenos derechos fue una de las principales demandas durante más de 25 años de las emisoras argentinas. Las asociaciones de radios comunitarias han sido protagonistas de esta lucha al convocar a otras organizaciones sociales a conformar la Coalición por una Radiodifusión Democrática, alianza que propuso los 21 Puntos por una Radiodifusión para la Democracia, en base a los cuales se formuló el proyecto de la después sancionada Ley de Servicios de Comunicación Audiovisual (LSCA) (SEGURA, 2011).

Numerosos organismos intergubernamentales destacan que los medios sin fines de lucro son centrales para garantizar el derecho a la comunicación en sociedades democráticas en un doble sentido. Por un lado, su presencia contribuye a configurar sistemas de medios más plurales y diversos, dado que se multiplican los sectores que participan de él. Por otro lado, constituyen escenarios de participación ciudadana que permiten la intervención de sujetos, temas y perspectivas que no suelen tener cabida en los medios privados-comerciales ni estatales. Por estas razones, exigen el reconocimiento legal de las emisoras no lucrativas en la sociedad (ver, por ejemplo, ONU, OEA, OSCE y CADHP, 2007; Comisión de Cultura y Educación del Parlamento Europeo, 2008; y OEA, 2010).

Según estos consensos internacionales, la libertad de expresión en un sentido amplio es indispensable para el desarrollo de una sociedad democrática, diversa y plural. Los medios de comunicación desempeñan una función social indispensable para la ampliación de perspectivas en el espacio público. Sin embargo, la creciente concentración de la propiedad de las empresas de medios y la mercantilización de la información pone de relieve que la cantidad de opciones mediáticas no siempre redunda en diversidad y pluralidad. Así, los medios sin fines de lucro se constituyen en garantes del ejercicio de la libertad de expresión.

Estos documentos consideran fundamental la intervención del Estado para garantizar el derecho humano a la comunicación. En particular, sostienen la necesidad de que los Estados reconozcan legalmente a los medios del tercer sector, que contemplen reservas de espectro para ellos y condiciones equitativas de acceso a las licencias con respecto a los medios estatales y privados comerciales 


\section{Políticas dirigidas a medios comunitarios, alternativos y populares}

En este apartado se revisa la historia de las políticas de radiodifusión dirigidas a medios comunitarios en Argentina desde 1980 en adelante. La formulación de políticas de comunicación en Argentina ha sido históricamente, desde los inicios de la radiodifusión, protagonizada por las elites políticas a cargo de los gobiernos y las elites económicas que controlaban las empresas de medios, en detrimento de los intereses ciudadanos (SEGURA y WAISBORD, 2016). En esta sección se evidencia que, en consecuencia, el sector no lucrativo ha sido el menos favorecido de la radiodifusión y estuvo signado siempre - excepto por escasos 10 años - por prohibiciones, discriminación y restricciones, que ahora se restauran.

\section{Ilegalidad (1980-2009)}

La Ley de Radiodifusión 22.285 y sus sucesivas modificatorias, que ordenaron las comunicaciones audiovisuales en Argentina desde 1980 y hasta 2009, establecían la prohibición de prestar servicios de comunicación audiovisual al sector privado sin fines de lucro. Esta inhabilitación legal se mantuvo hasta 2005.

Con la recuperación del régimen constitucional de gobierno en 1983, el ex presidente Raúl R. Alfonsín suspendió la aplicación del Plan Nacional de Radiodifusión (PLANARA) que la Junta Militar había aprobado en 1981 para implementar los concursos para la adjudicación de frecuencias de radiodifusión. Por la ausencia de un plan técnico que permitiera licitar o asignar nuevas licencias, junto con el abandono del proyecto de nueva ley de radiodifusión de la democracia, durante las décadas de 1980 y 1990 se establecieron en todo el país miles de radios sin licencia; entre ellas, las comunitarias. Estas, quedaron confinadas a una ilegalidad generalmente tolerada por los organismos de control - aunque a veces fueron reprimidas - y sin control de las interferencias producidas a sus señales por otras emisoras.

En 1989, la Ley 23.696 de Reforma del Estado dictada durante la presidencia de Carlos S. Menem, facultaba al Poder Ejecutivo Nacional, hasta tanto se dictara una nueva ley de radiodifusión, para "adoptar las medidas necesarias" para regular el funcionamiento de "aquellos medios que no se encuentren encuadrados en las disposiciones vigentes hasta el momento de la sanción de esta ley de emergencia”, lo que incluía a los medios comunitarios. Luego, por decreto 1357/89, se abrió un registro para las emisoras que estuvieran en el aire con fecha anterior al día de sanción de la ley (agosto de 1989), y se les entregó un permiso provisorio para poder emitir hasta tanto se abrieran nuevos concursos. Esta maniobra tuvo algunas consecuencias: primero, las radios se dividieron entre las ahora "provisorias" y las "clandestinas" (Ley 22.285); segundo, se logró el control sobre las emisoras, que para obtener el permiso debían "ficharse" en el Comité Federal de Radiodifusión (COMFER); y tercero, generó mayor confusión, puesto que los permisos caducaban el día del llamado a concurso, que se realizaría bajo las mismas 
condiciones restrictivas de la 22.285. No obstante, debido a una serie de irregularidades, el concurso finalmente no se llevó adelante. Frente a esto, las emisoras comunitarias se presentaron ante la justicia y lograron resoluciones favorables a sus pedidos de amparo, aunque no pudieron salir de la precariedad legal (VINELLI, 2014).

Las televisoras sin fines de lucro corrieron peor suerte. Si bien el decreto 1.357/89 preveía registrar en una segunda etapa a la TV, la inscripción para estas últimas nunca se abrió. Salvo unos pocos amparos, no hubo permisos precarios para los canales barriales. Según los periódicos de la época, frente a los pronunciamientos de la Asociación de Teledifusores Argentinos (ATA), el Estado respondía con el allanamiento y la clausura de las emisoras comunitarias (VINELLI, 2014).

\section{Legalización (2009-2015)}

En 2003, dos fallos históricos de la Corte Suprema de Justicia de la Nación declararon la inconstitucionalidad del artículo 45 de la Ley 22.285 que impedía a los medios no lucrativos prestar servicios de radiodifusión. En 2005, durante la presidencia de Néstor C. Kirchner, el Congreso, por Ley 26.053, sustituyó este artículo y permitió que personas jurídicas sin fines de lucro sean titulares de licencias de radiodifusión.

Desde entonces, se registraron algunos avances en reconocimiento legal. El COMFER otorgó la primera licencia a una radio indígena en el país en 2005. En 2006, reconoció y autorizó a funcionar - aunque sin licencia - a 126 radios pertenecientes a organizaciones sin fines de lucro que ya estaban en actividad (Res. 753). En 2007, otorgó la licencia a la Radio de las Madres de Plaza de Mayo y a Radio Encuentro.

En 2009, durante la presidencia de Cristina Fernández, el Congreso sancionó la LSCA n 26.522. La ley establece: "la explotación de los servicios de comunicación audiovisual podrá ser efectuada por prestadores de gestión estatal, de gestión privada con fines de lucro y de gestión privada sin fines de lucro". A estos últimos, les reserva el 33\% del espectro radioeléctrico, no le impone restricciones de alcance ni financiamiento, establece un fondo de fomento del $10 \%$ del gravamen recaudado por la autoridad regulatoria, les da representación en el Consejo Federal de Servicios de Comunicación Audiovisual (COFECA), y agrega la posibilidad de otorgar licencias de modo directo a emisores de baja potencia en zonas de no conflicto.

Desde entonces, son pocos los medios sin fines de lucro que obtuvieron licencias y recibieron habilitación para funcionar. Unos obtuvieron licencias recientemente, pero aún no cuentan con habilitación definitiva para operar; otros recibieron permisos precarios - y algunos de ellos con reserva de frecuencia -; y a otros se les adjudicó frecuencias para emitir en baja potencia. Son todavía muchos los que no cuentan con un título que les permita operar legalmente (BECERRA y otros, 2016). 
En los casos que se hicieron concursos de licencias, hasta 2015 no se avanzó en ampliar las condiciones diferenciadas para las televisoras no lucrativas, dificultando que medios en funcionamiento se pudieran presentar; generando lentitud en la legalización y debilitamiento en las condiciones de funcionamiento. Además, la lentitud en la preparación del plan técnico de frecuencias digitales, elaborado en noviembre de 2014, llevó a que los concursos en televisión digital convocados por la Autoridad Federal de Servicios de Comunicación Audiovisual (AFSCA) se sustanciaran sobre el fin de la gestión del gobierno de Cristina Fernández. La especificidad de los medios comunitarios dentro de la categoría más amplia de los prestadores sin fines de lucro se reconoció tardíamente, en diciembre de 2015, con la Resolución 1.102, que reconoció a unas 150 emisoras de radio sin fines de lucro previamente registradas o empadronadas, en su carácter de comunitarias; y estableció que estas emisoras recibirían un puntaje preferencial en futuros concursos.

Entre 2012, cuando AFSCA puso en marcha el Fondo de Fomento Concursable para Medios de Comunicación Audiovisual (FOMECA), dando cumplimiento al artículo 97 de la Ley 26.522, y, hasta 2015, realizó 18 concursos públicos y concedió 380 premios a los equipos técnicos, infraestructura tecnológica, la producción de radio y televisión, y la gestión de los medios comunitarios, entre otros aspectos (BECERRA y otros, 2016).

Los FOMECA permitieron a los medios del sector social mejorar su posición en un mercado hiper-comercial. Les posibilitaron equiparse para avanzar en la transición a tecnología digital, producir contenidos gratuitos y abiertos con altos estándares de calidad, contratar servicios y rendir honorarios temporarios para la realización de materiales audiovisuales y radiofónicos, y regularizar la gestión de radios, canales y productoras audiovisuales.

\section{Regresión (2015 a 2017)}

Estos avances se detienen a partir de diciembre de 2015, cuando el presidente Mauricio Macri impuso los Decretos de Necesidad y Urgencia (DNU) 13 y 267, ratificados por la Cámara de Diputados en 2016, que modifican la LSCA. Aunque ambos decretos no eliminaron ni modificaron los artículos referidos a los medios privados sin fines de lucro - excepto a las cooperativas de servicios públicos que prestan servicios de televisión de pago -, todas las políticas desarrolladas desde entonces se caracterizan por la persecución y el ahogo financiero, mientras el Estado incumple con su obligación de legalizar y fomentar a estas radios y televisoras.

Las nuevas políticas se expresan, por un lado, en decomisos e intimaciones a emisoras comunitarias que padecen la ilegalidad en diferentes puntos del país y, por otro, en la dilación en la ejecución de fondos de fomento, intimaciones por supuestas irregularidades en la rendición de fondos y desprestigio del Fondo y de las radios y televisoras comunitarias.

Los procesos de legalización de las radios y televisoras comunitarias se interrumpieron abruptamente al asumir el nuevo gobierno. No se terminaron de resolver algunos concursos iniciados en 2015; no se tramitaron las 
habilitaciones de las emisoras que habían ganado licencias en otros concursos realizados también ese año; ni se resolvieron administrativamente conflictos por interferencias hasta diciembre de 2016, tras reuniones, presentaciones de documentos y protestas callejeras realizadas por Espacio Interredes, que nuclea a las asociaciones nacionales de medios no lucrativos. Ese mes, el nuevo organismo de regulación de la comunicación audiovisual y las telecomunicaciones, el Ente Nacional de Comunicaciones (ENACOM), resolvió el conflicto por la interferencia que el Grupo Clarín hacía en la señal asignada a dos de las tres primeras televisoras comunitarias (de Ciudad de Buenos Aires) que ganaron su licencia en concursos realizados en 2015: les asignó otra señal. También resolvió un concurso iniciado en 2014 y otorgó la licencia a una radio cooperativa de la provincia de Córdoba. No obstante, suspendió concursos que habían sido llamados en 2015 y que perjudican a televisoras comunitarias de provincia de Buenos Aires y Mendoza. Además, quedaron pendientes de resolución solicitudes de prórroga de la habilitación definitiva para radios que habían ganado sus licencias en 2015 y solicitudes de autorización de radios de baja potencia.

A abril 2017, el ENACOM adeuda pagos de cuotas a más de 200 proyectos adjudicados del FOMECA 2015 por más de 25 millones de pesos, según calculó el Espacio Interredes, que nuclea a las asociaciones nacionales de medios del sector social.

El ENACOM llamó a concursos del FOMECA 2016 recién en noviembre de ese año, sin conocerse los ganadores. Paralelamente, el ente intima a las emisoras por supuestas irregularidades en la rendición del FOMECA con una estrategia de dilación y desprestigio que dificulta el acceso a los fondos previstos en la ley.

Además, se desfinanciaron programas de diversos organismos públicos destinados al desarrollo o el fortalecimiento de medios de comunicación sin fines de lucro, como los proyectos "Sembramos Palabras, Cosechamos Derechos", "Radios comunitarias rurales. Comunicarnos fortalece", y el convenio para que las bibliotecas populares fomenten medios comunitarios. Se interrumpió la distribución de pauta oficial a emisoras sin fines de lucro, ya que el criterio de distribución es el nivel de audiencia de medios en grandes ciudades.

El DNU 267 implicó la pérdida del espacio de participación e incidencia en la formulación de políticas de comunicación que los medios no lucrativos tenían en el COFECA, al eliminarse esta institución. En agosto de 2016, se creó el Consejo Federal de Comunicaciones (COFECO) unificando el COFECA y el Consejo Federal de Tecnologías de las Telecomunicaciones y la Digitalización. Esto redujo la cantidad de representantes del sector sin fines de lucro de 3 a 1 y unificó a los prestadores de servicios de comunicación audiovisual con los de telecomunicaciones. Además, le quitó funciones al consejo como nombrar y remover integrantes del directorio o tomar decisiones relativas a los FOMECA. El COFECO se reunió por primera vez 11 meses después de disuelto el COFECA y el representante propuesto por las radios comunitarias no fue convocado 


\section{Políticas dirigidas a medios comerciales}

Aquí, se revisan las principales políticas que generaron en Argentina un sistema mediático mercantil y altamente concentrado y produjeron condiciones desiguales para el ejercicio de la libertad de expresión.

La Ley 22.285 configuraba la comunicación como un bien comercial con control del Estado era "el resultado de las coincidencias de los intereses del Estado (control ideológico) y los empresarios (fines de lucro)” (POTOLSKI Y MARINO, 2005, p. 175).

En 1989, presidencia de Carlos S. Menem, la Ley 23.696 de Reforma del Estado consagró la "desregulación, privatización, desmonopolización" para todas las políticas públicas incluyendo las de comunicaciones y flexibilizó "puntos clave de la ley 22.285 que imposibilitaban hasta el momento la constitución legal de conglomerados en forma de multimedios" (ROSSI, 2005, p. 237). Esto facilitó la "presencia del capital financiero transnacional, concentración y centralización del capital, incorporación intensiva de nuevas tecnologías y expansión de los servicios ofertados" (ALBORNOZ y HERNÁNDEZ, 2005, p. 259).

La Ley de Reforma del Estado habilitó la titularidad de las licencias de radiodifusión a sociedades de empresas; y la posibilidad de que las empresas licenciatarias de medios de comunicación pudieran ser también propietarias de empresas dedicadas a otros sectores de la economía. Además, la aprobación de un tratado internacional de reciprocidad con Estados Unidos habilitó a los norteamericanos a ser radiodifusores en la Argentina en las condiciones de la legislación de aquel país. Un DNU permitió las transferencias inmediatas de titularidad de licencias (LORETI, 2003) y otro posibilitó que los licenciatarios tuvieran la titularidad de hasta 24 servicios de radiodifusión.

El período 1989-1999 es reconocido como "la primera fase expansiva de la concentración del sistema de medios argentino" gracias a la entrega de privilegios impositivos, la legalización de la operación de redes, el aumento al tope en la propiedad de licencias del mismo operador y la autorización para la constitución de multimedios (BECERRA, 2015, p. 17). Se produjo la "exacerbación del modelo privado-comercial" (ROSSI, 2005, p. 235) y la "liberalización controlada del sistema, con actores privados reteniendo el control sobre las cuestiones claves del proceso" (MASTRINI, 2010, 161).

En 2003, al inicio de la presidencia de Néstor C. Kirchner, el Congreso aprobó la Ley 25.750 de Preservación de Bienes y Patrimonios Culturales que impide a capitales extranjeros poseer más del $30 \%$ de la propiedad de las industrias culturales, pero excluye de esta disposición a los medios que, al momento de sancionarse la ley, tuvieran una presencia mayor de capitales extranjeros. La norma apuntaba a "evitar que aquellos grupos que aún no habían quedado en manos del capital extranjero sean absorbidos por sus acreedores externos por no pagar" las deudas asumidas para sostener el proceso de concentración de propiedad (MASTRINI y otros, 2005, p. 21-22). 
En 2004 el COMFER renovó las licencias de los dos canales de rating promedio más alto de la televisión argentina, el 11 y el 13, en beneficio de sus propietarios privados, Telefónica y el Grupo Clarín, "para que puedan atravesar sus difíciles situaciones económicas” (MARINO, 2005, p. 14). No obstante estas prórrogas y que el vencimiento de las licencias no era inminente en 2005, por medio del Decreto 527, el presidente Kirchner suspendió por 10 años el vencimiento de las licencias a los propietarios de los medios masivos de comunicación. Con esta medida, se suspendió el cómputo de los plazos que la ley otorgaba de quince años más diez de prórroga por única vez, extendiendo por otros 10 el término original. Además, en diciembre de 2007, en el último día hábil de su mandato, Kirchner autorizó por decreto la fusión de los dos mayores operadores de televisión por cable de la Argentina: Cablevisión y Multicanal. Esta medida implicó otorgarle al Grupo Clarín casi el monopolio de este negocio en gran parte del territorio nacional.

En 2009, la LSCA estableció límites a la concentración de la propiedad (arts. 45, 46, 47, 48, 54), la propiedad cruzada, la transmisión en cadena, la centralización de la producción y plazos de propuestas de planes de adecuación para las empresas que excedieran los límites establecidos. Luego de que la Corte Suprema de Justicia de la Nación declarara la constitucionalidad plena de la LSCA, todas las empresas en esta situación presentaron sus planes de adecuación ante la autoridad regulatoria; algunos fueron evaluados y aprobados, pero ninguno implementado.

En diciembre de 2015, el Poder Ejecutivo Nacional modificó sustancialmente la LSCA mediante dos DNU ratificados por la Cámara de Diputados en abril de 2016; se posibilitó aumentar los límites de concentración de la propiedad de radio y televisión abierta; eliminarlos para TV por cable; permitió la propiedad cruzada entre empresas audiovisuales y de telecomunicaciones y se extendió el plazo de explotación de las licencias audiovisuales vigentes.

El ENACOM dejó sin efecto los planes de desinversión presentados por los grupos de medios que superaban los límites establecidos por la LSCA. Asimismo, el gobierno condonó las deudas impositivas, previsionales y aduaneras a los medios comerciales a cambio de publicidad oficial, lo que implica una millonaria transferencia de ingresos del Estado a estas empresas.

A un año de su mandato, el gobierno confirmó por decreto 1.340/16 la "convergencia plena" para 2018, lo que implica que los tres o cuatro principales operadores podrán "hacer todo" mientras se tapona el ingreso de otros nuevos que no sean los ya dominantes en cada segmento, no establece disposiciones de protección ni fomento para pequeñas y medianas empresas, cooperativas ni otros actores no lucrativos, relaja las obligaciones de los operadores y no establece exigencias de interés público. Profundiza, por lo tanto, la concentración en el sector audiovisual y de telecomunicaciones (BECERRA, 2017). 


\section{Políticas dirigidas a medios estatales}

Argentina fue el primer país latinoamericano en instalar una televisión estatal.

A pesar de relegarlos con respecto a los medios privados, todos los gobiernos los mantuvieron por razones similares a las que fundamentan la necesidad de promoción de los medios comunitarios. No obstante, los medios públicos, constituyen una política de Estado.

Según la Ley 22.285, los medios estatales mantuvieron, desde 1980 y hasta mediados de la década 2000, un rol subsidiario en el sistema mediático. Se instalaban sólo en zonas de frontera o en lugares que no eran de interés de los privados. En los 90` se privatizaron los canales 11, 13 y las radios Belgrano y Excelsior de Capital Federal el sistema público quedó reducido al Servicio Oficial de Radiodifusión integrado por una radio y una televisora de cabecera en Capital Federal, una estación de radio en cada provincia, las repetidoras del canal de televisión y las estaciones de Radiodifusoras Argentinas al Exterior. En 1992, el canal se convierte en una Sociedad Anónima por decreto presidencial. Los contenidos de los medios de comunicación estatales "no ofrecieron perfiles diferentes a los privados comerciales ni tampoco favorecieron la participación social" (ROSSI, 2005).

Asimismo, estos medios padecieron un retraso tecnológico la crisis presupuestaria e institucional del Estado. En Canal 7 esto se combinó con irregularidades administrativas que derivaron en la propuesta de privatización por parte del Poder Ejecutivo, iniciativa que no se concretó por la resistencia de los trabajadores (MÍNDEZ, 2001). En tanto, en Radio Nacional se produjo una política de reducción de personal que afectó tanto a la cabecera como a las radios de la red nacional en las provincias (ULANOVSKY, 2011).

A poco de culminar el segundo gobierno de Menem, el Congreso aprobó la Ley RTA (Radio y Televisión Argentina), que dotaba por primera vez en la historia del país a los medios estatales nacionales de una institucionalidad pública, con un directorio específico, control parlamentario y objetivos como la garantía del pluralismo y servicio universal. La norma fue vetada por Fernando De la Rúa apenas asumió en 1999 y en su lugar creó por decreto una nueva institución para la administración de estos medios: el Sistema Nacional de Medios Públicos. Además de restituir la subsidiariedad del servicio, la norma dejaba a la nueva institución en manos del Ejecutivo sin contrapesos ni controles parlamentarios.

El rol subsidiario de los medios estatales nacionales en el sistema mediático comenzó a ser revertido con el Decreto 2.368 de 2002, durante el gobierno interino de Eduardo Duhalde, en tanto autorizaba la instalación de repetidoras de Canal 7 donde el Ejecutivo lo considerase, y luego el Decreto 1.214 de 2003 legalizó una situación existente con la autorización a provincias para contar con un canal abierto y una radio AM. 
A esto se sumó la firma de los decretos 84, 134 y 365 del ex presidente Kirchner en 2005 que autorizaron la instalación de 20 repetidoras de Canal 7 en centros urbanos de todo el país. Además, se pusieron en marcha dos nuevas iniciativas de televisión pública: la inclusión de Argentina en la televisora sudamericana Telesur en 2004 y la creación de Canal Encuentro dependiente del Ministerio de Educación, Ciencia y Tecnología de la Nación en 2005: “por primera vez en Argentina se creó un canal educativo y cultural destinado a difundirse mediante el sistema de cable" (MONJE, 2010, p. 190). En 2005, aumentó el presupuesto para Canal 7 y Radio Nacional, se envió una reasignación presupuestaria para salarios y compra de nuevos equipos, y se instalaron nuevas antenas repetidoras en 17 nuevas ciudades. A partir de 2007 se modificó también la programación del Canal 7, con "una propuesta de contenidos que rompe con el modelo competitivo-comercial” (MONJE, 2010, p. 206).

En 2009, la LSCA incluyó 26 artículos específicos sobre medios públicos-estatales. En ellos se deja atrás el rol subsidiario y se crea Radio y Televisión Argentina Sociedad del Estado para administrar a los medios preexistentes del Estado nacional. Entre sus obligaciones y objetivos, se atiende a la garantía de cubrir todo el territorio nacional, promoción del pluralismo y el federalismo, producción propia, difusión de la producción audiovisual nacional, regional y latinoamericana. Como novedad, la norma otorga pautas de financiamiento, indicaciones de transparencia y establece la conformación plural del directorio de la sociedad, además de un diseño institucional para potenciar la participación, el control de diferentes sectores sociales y el equilibrio de poderes del Estado (LINARES, 2014). No obstante, los integrantes del Consejo Honorario de Medios Públicos, institución creada por la LSCA, fueron designados por el Poder Ejecutivo recién en 2015 y llegaron a tener apenas una reunión antes del cambio de gobierno.

Además, desde 2010 se crearon otras siete señales de televisión específicas gestionadas por diferentes áreas del gobierno nacional, y sólo se transmiten por la televisión digital. Estos canales digitales han hecho innovaciones en la calidad, la diversidad y el federalismo de su contenido, y en su propuesta educativa, cultural y de entretenimiento. Asimismo, AFSCA otorgó autorizaciones a nuevos canales provinciales, municipales y universitarios.

En diciembre del 2015, por el Decreto 12, se crea el Sistema Federal de Medios y Contenidos Públicos con la facultad de poder coordinar con el Ministerio de Educación y Deportes el contenido y funcionamiento de las señales Encuentro, Paka Paka, DeporTV, el Banco Audiovisual de Contenidos Universales Argentinos y el Polo de Producción Audiovisual. Así, se reforma la Ley 26.522 por decreto y además cambia, sin consulta ni debate previo, la orientación específicamente cultural y educativa de estos canales. Hubo, además, despidos de trabajadores, retrocesos en las coberturas a los juicios por crímenes de lesa humanidad, incumplimiento de la cuota de pantalla infantil y la federalización de contenidos (CONSEJO CONSULTIVO DE MEDIOS PÚBLICOS, 2016). Se busca así restituir también el rol subsidiario de los medios estatales. 


\section{Conclusiones}

Históricamente se sostuvieron los privilegios del sector privado-comercial (con financiamientos directos e indirectos del Estado: subsidios, exenciones impositivas, ampliación de plazos de vencimiento de licencias, facilidades para transferir licencias y fusionar sociedades, condonación de deudas con el fisco, publicidad oficial) y el financiamiento del sector público-estatal, en desmedro del sector privado sin fines de lucro.

No obstante, la LSCA sancionada en 2009 implicó un intento de poner límites a la concentración de la propiedad privada de medios, la jerarquización y multiplicación de los medios públicos-estatales, junto con la legalización y fomento de los medios no lucrativos. No obstante, durante su implementación no se llegó a revertir las condiciones de profunda desigualdad del sistema mediático del país.

A partir de diciembre de 2015, se evidencia un retroceso con respecto a aquellos adelantos. Se produce una regresión en los derechos adquiridos a partir de la restauración y profundización de la orientación histórica de las políticas de comunicación que privilegiaba a los medios comerciales, dejaba a los estatales en un rol subsidiario, y perseguía o - en el mejor de los casos - ignoraba a los comunitarios. La diferencia es que ahora las emisoras del sector social son reconocidas legalmente y el Estado tiene la obligación de arbitrar los mecanismos necesarios para que accedan a sus licencias, en lugar de perseguirlas por "clandestinas".

Dada la histórica marginación que ha sufrido esta forma de expresión mediática en las políticas y legislaciones destinadas al sector audiovisual resulta difícil imaginar que estos medios puedan competir en igualdad de condiciones con actores privados que han sido beneficiados por el accionar estatal a lo largo de la historia.

Por lo tanto, así como el Estado, por acción u omisión, fue un actor clave en el sostenimiento y profundización de las profundas desigualdades en las políticas de comunicación en detrimento de las emisoras de radio y televisión comunitaria, popular y alternativa con respecto a otros medios audiovisuales; también lo es para saldar la deuda histórica que mantiene con el sector de medios no lucrativos, las organizaciones sociales que los sostienen desde hace ya tres décadas en condiciones de precariedad legal y económica, sus públicos y la sociedad en general.

\section{Referências}

ALBORNOZ, Luis y HERNÁNDEZ, Pablo. La radiodifusión en Argentina entre 1995 y 1999: concentración, desnacionalización y ausencia de control público. Mucho ruido, pocas leyes. Economía y politicas de comunicación en la Argentina (1920-2004). Buenos Aires: La Crujía. p. 257- 286, 2005.

BECERRA, Martín. A falta de inversiones, llueven decretos. Quipu. Políticas y tecnologías de comunicación, enero 2017. Disponible en: https://martinbecerra.wordpress.com/2016/03/09/ socorro-estatal-a-medios-con-deudas/ 
- Socorro estatal a medios con deudas. La saga continúa. Quipu. Políticas y tecnologías de comunicación, marzo 2016. Disponible en: https://martinbecerra.wordpress.com/2016/03/09/ socorro-estatal-a-medios-con-deudas/

. La pauta que los parió. Quipu. Politicas y tecnologías de comunicación. Disponible en https://martinbecerra.wordpress.com/2016/03/02/ la-pauta-que-los-pario/ Marzo 2016-2.

. De la concentración a la convergencia, Buenos Aires: Paidós, 2015.

y otros. Diagnóstico sobre el acceso del sector sin fines de lucro a medios audiovisuales en la Argentina. Los medios sin fines de lucro entre la Ley Audiovisual y los decretos. Estrategias, desafios y debates en el escenario 2009-2015. Córdoba: Editorial de la UNC, 2016.

COMISIÓN DE CULTURA Y EDUCACIÓN DEL PARLAMENTO EUROPEO. Informe sobre los medios del tercer sector de la comunicación, 2008.

COALICIÓNPORUNARADIODIFUSIÓNDEMOCRÁTICA.21 puntosbásicosporelDerechoalaComunicación,BuenosAires,2004.Disponibleen: https:/drive.google.com/file/d/0By-8Cmgn08h6MFA0QlhXaVVYZ3M/ view?usp=sharing\&pref $=2 \& \mathrm{pli}=1$

CONSEJO CONSULTIVO DE MEDIOS PÚBLICOS. Evaluación de programación, contenidos y funcionamiento de RTA, 2016.

ENACOM. 17 principios que regirán la ley de comunicaciones convergentes, Buenos Aires, 2016. Disponible en: http://www.enacom.gob.ar/institucional/ la-comision-redactora-presento-los-17-principios-de-la-nueva-ley_n1271

GERBALDO, Judith. Radios comunitarias de América Latina y Argentina. Marcas de época en la acción política y comunicativa, 2012. Disponible en: http://eci.sociales.uba.ar/2012/10/07/radios-comunitarias-de-america-latina-y-argentina-marcas-de-epoca-en-la-accion-politica-y-comunicatival

KEJVAL, Larisa. Significaciones en torno a las radios comunitarias, populares y alternativas argentinas. Tesis de Maestría en Comunicación y Cultura. Buenos Aires: Facultad de Ciencias Sociales de la UBA, 2013.

LINARES, Alejandro. Servicio Público de Radiodifusión en la Ley de Servicios de Comunicación Audiovisual de Argentina - LSCA (20092014). Revista Estado y Políticas Públicas. Año II, n. 3. Buenos Aires: FLACSO, 2014.

LORETI, Damián. América Latina y la libertad de expresión. Bogotá: Norma, 2005.

MARINO, Santiago. Políticas de comunicación del sector audiovisual: las paradojas de modelos divergentes con resultados congruentes. Los casos de la Televisión por Cable y el Cine en Argentina entre 1989-2007. Tesis doctoral. Buenos Aires: Facultad de Ciencias Sociales (UBA), 2012. 
MASTRINI, Guillermo; BECERRA, Martín; BARANCHUK, Mariana y ROSSI, Diego. Introducción. Mucho ruido, pocas leyes. Economía y políticas de comunicación en la Argentina (1920-2004). Buenos Aires: La Crujía. p. 11-28, 2005.

La televisión estatal en la Argentina: entre el poder político y el negocio. La palabra empeñada. Investigaciones sobre medios y comunicación pública en Argentina. Buenos Aires: C3 Fundación Friedrich Ebert, 2010.

MíNDEZ, Leonardo. Canal 7. Medio Siglo Perdido. Buenos Aires: La Crujía, 2001.

MONJE, Daniela. Políticas de radiodifusión frente a procesos de integración regional: Caso MERCOSUR 1991-2007. Tesis para optar al grado de Doctora en Ciencias Sociales. Buenos Aires: FLACSO, 2010.

POSTOLSKY, Glenn y MARINO, Santiago. "Relaciones peligrosas: los medios y la dictadura entre el control, la censura y los negocios". Mucho ruido, pocas leyes. Economía y politicas de comunicación en Argentina (1920-2004). Buenos Aires: La Crujía. p.155- 184, 2005.

ROSSI, Diego. La radiodifusión entre 1990-1995: exacerbación del modelo privado-comercial. Mucho ruido, pocas leyes. Economía y políticas de comunicación en Argentina (1920-2004). Buenos Aires: La Crujía. p. 235-256, 2005.

SEGURA, María Soledad. La sociedad civil y la democratización de las comunicaciones en la Argentina. La experiencia de la Coalición por una Radiodifusión Democrática. Argumentos. Revista de Crítica Social, n. 13, Buenos Aires: Instituto Gino Germani, Facultad de Ciencias Sociales, UBA, 2011. Disponible en: http://argumentos.fsoc.uba.ar

SEGURA, María Soledad y WAISBORD, Silvio. Media movements. Civil society and media policy reform in Latin America, Londres; Zedbooks, 2016.

ULANOVSKY, Carlos. La Radio Nacional. Voces de la historia. 19372011. Buenos Aires: Colihue, 2011.

VINELLI, Natalia. (comp.) La televisión desde abajo. Historia, alternatividad y periodismo de contrainformación. Buenos Aires: El topo blindado/El río suena, 2014.

\section{Notas}

1. Os autores do artigo são docentes pesquisadores de universidades públicas e do Consejo Nacional de Investigaciones Científicas y Técnicas (Conicet) da Argentina, integrantes do projeto "Las radios y televisoras comunitarias desde la Ley 26522. Condiciones, estrategias y desafíos" (financiado pelo Conicet e pelo DPSCA, desde 2015). 